\title{
Combination of histidine, lysine, methionine, and leucine promotes $\beta$-casein synthesis via the mechanistic target of rapamycin signaling pathway in bovine mammary epithelial cells
}

\author{
H. N. Gao, ${ }^{*} \ddagger \ddagger \S^{1}$ S. G. Zhao, ${ }^{\star} \ddagger \S^{1}$ N. Zheng, ${ }^{\star} \ddagger \S^{1}$ Y. D. Zhang, ${ }^{\star} \ddagger \S$ S. S. Wang, ${ }^{\star} \ddagger \S$ X. Q. Zhou, ${ }^{\star} \ddagger \S$ \\ and J. Q. Wang ${ }^{*} \dagger \pm \S^{2,3}$ \\ *Ministry of Agriculture-Milk Risk Assessment Laboratory, Institute of Animal Science, Chinese Academy of Agricultural Sciences, \\ Beijing 100193, China \\ †College of Animal Science and Technology, Gansu Agricultural University, Lanzhou 730070, China \\ †Ministry of Agriculture-Milk and Dairy Product Inspection Center, Beijing 100193, China \\ $\S$ State Key Laboratory of Animal Nutrition, Institute of Animal Science, Chinese Academy of Agricultural Sciences, Beijing 100193, China
}

\begin{abstract}
The ratio of different $\mathrm{AA}$ in the diets of cows is vital to improve milk protein yield. $\beta$-Casein is one of the important milk proteins with high nutritive value. However, the suitable ratio of essential amino acids (EAA) for the expression of $\beta$-casein in the immortalized bovine mammary epithelial cell line is not fully characterized. This study employed response surface methodology to determine the optimal ratio of His, Lys, Met, and Leu on $\beta$-casein expression level in vitro and clarified the effect of the 4 EAA on $\beta$-casein via the mechanistic target of rapamycin (mTOR) signaling pathway. A central composite design containing 5 axial points per EAA and 28 combinations of the 4 EAA was used in our study. The results of response surface methodology and the changes of the mTORrelated signaling proteins were determined by western blot. The results showed that $\beta$-casein level was significantly affected by all 4 EAA $\left(\mathrm{R}^{2}=0.71\right)$. The optimum conditions for $\beta$-casein expression are found to be 5.47 $\mathrm{m} M$ of His, $7.48 \mathrm{~m} M$ of Lys, $1.17 \mathrm{~m} M$ of Met, and $8.21 \mathrm{~m} M$ of Leu (His:Lys:Met:Leu $=5: 6: 1: 7$ ) in the designed scope of concentration. The interaction of Leu and Met significantly affected $\beta$-casein expression $(P<$ $0.01)$. The phosphorylation of $\operatorname{mTOR}\left(\operatorname{Ser}^{2481}\right)$, regulatory associated protein of target of rapamycin (Ser ${ }^{792}$ ), ribosomal protein S6 kinase $1\left(\mathrm{Thr}^{389}\right)$, ribosomal protein S6 ( $\left.\operatorname{Ser}^{235 / 236}\right)$, and eukaryotic elongation factor $2\left(\mathrm{Thr}^{56}\right)$ was increased with the supplementation of

\footnotetext{
Received December 6, 2015.

Accepted February 22, 2017.

${ }^{1}$ These authors contributed equally.

${ }^{2}$ Current address: State Key Laboratory of Animal Nutrition,

${ }^{3}$ Corresponding author: wang-jia-qi@263.net
} Institute of Animal Science, Chinese Academy of Agricultural Sciences, No. 2 Yuanmingyuan West Road, Haidian District, Beijing, 100193, P. R. China.
\end{abstract}

either single EAA or an optimal combination of EAA. However, the phosphorylation of eukaryotic initiation factor $4 \mathrm{E}$ binding protein $1\left(\mathrm{Thr}^{37}\right)$ was decreased with the addition of Lys, Met, or Leu alone. Furthermore, the phosphorylation $(\mathrm{P})$ of eIF $2 \alpha\left(\mathrm{Ser}^{51}\right)$ was decreased when Met was supplemented alone. Under the optimal mixture of 4 EAA, the phosphorylation of mechanistic target of rapamycin complex 1 signaling proteins was significantly greater than the single EAA supplementations and the expression of $\beta$-casein was $98 \%$ as high as the positive control (i.e., medium with all AA). A similar trend was found with P-ribosomal protein S6 kinase 1 and P-ribosomal protein S6. In conclusion, the extracellular concentrations of His, Lys, Met, and Leu at a ratio of 5:6:1:7 maximized $\beta$-casein expression in the immortalized bovine mammary epithelial cell line may occur via activation of the mechanistic target of rapamycin complex 1 signaling pathway.

Key words: bovine mammary epithelial cells, mechanistic target of rapamycin, $\beta$-casein, essential amino acid

\section{INTRODUCTION}

The lactating bovine mammary gland is a potent milk protein synthesizing factory (Patton, 1969). Milk protein is composed of casein $(80 \%)$ and whey protein (McLean et al., 1984). Casein is a protein of high human nutritional value and is used as an important index to measure the quality of milk (Fox and Sweeney, 2003). $\beta$-Casein is one of the 4 casein proteins and constitutes about $30 \%$ of the total casein (Bionaz et al., 2012).

The amount of the essential amino acids (EAA) in the diet is important for milk protein synthesis, but the ratio of EAA in the diet is more important. (Park et al., 1976; Haque et al., 2012). Nan et al. (2014) revealed that the ratio of Met to Lys had a significant influence on the expression of casein in bovine mammary 
epithelial cells (CMEC). It was also reported that milk protein synthesis efficiency was $24.7 \%$ under a grassbased diet with $17.8 \%$ CP (Hristov et al., 2004), but this efficiency increased to $30.0 \%$ under a grass-based diet with a well-balanced addition of His, Lys, Met, and Leu even when the dietary CP was 15.0\% (Haque et al., 2012). Similarly, supplying the 4 EAA (Lys, Met, His, and Leu) also increases the milk protein yield (Haque et al., 2012).

According to previous studies, His, Lys, Met, and Leu were not only the main limiting EAA in grassbased diets (Kim et al., 1999, 2000, 2001; Korhonen et al., 2002; Weekes et al., 2006; Lapierre et al., 2008), but they also were key intracellular factors presumably regulating milk protein synthesis via the mechanistic target of rapamycin complex 1 (mTORC1) pathway in CMEC (Prizant and Barash, 2008; Appuhamy et al., 2012; Wang et al., 2014). The mTORC1 consists of the mechanistic target of rapamycin (mTOR), the regulatory associated protein of target of rapamycin (Raptor), and the $\mathrm{G}$ protein $\beta$ subunit-like protein (GßL; Kim, 2009). When mTORC1 is activated by AA, it triggers the phosphorylation of the ribosomal protein S6 kinase 1 (S6K1), eukaryotic initiation factor $4 \mathrm{E}$ binding protein 1 (4EBP1), and ribosomal protein S6 (RPS6) to stimulate mRNA translation (Anthony et al., 2000; Prizant and Barash, 2008; Appuhamy et al., 2012). In addition, eukaryotic elongation factor 2 (eEF2) is phosphorylated on Thr56 and may be inhibited by mTORC1 or enhanced by adenosine monophosphate-activated protein kinase (AMPK), which may be a limiting factor in milk protein synthesis (Christophersen et al., 2002; Arriola Apelo et al., 2014a).

The objectives of this study were to identify the optimal ratio of His, Lys, Met, and Leu for $\beta$-CN protein synthesis and to examine the role of mTORC1 pathway in regulating $\beta-\mathrm{CN}$ synthesis with respect to the optimum supplementations of the EAA in the immortalized bovine mammary epithelial cell line (CMEC-H).

\section{MATERIALS AND METHODS}

\section{Materials}

The individual AA (L-His, L-Lys, L-Met, and L-Leu, catalog no. H5659, L8662, M5308, and L8912, respectively) were purchased from Sigma-Aldrich (Shanghai Trading Co. Ltd., Shanghai, China). The total and site-specific phosphorylated antibodies against mTOR (Ser ${ }^{241}$, catalog no. 2913/YP1134), 4EBP1 ( $\mathrm{Thr}^{37}$, catalog no. 0018/YP0001), RPS6 (Ser ${ }^{23 / 236}$, catalog no. 4139/YP0832), and eIF2 $\alpha$ ( $\mathrm{Ser}^{51}$, catalog no. 1507/ YP0093) were purchased from Immuno Way (Immuno Way Biotechnology Company, Barksdale Professional
Center, Newark, DE). The total and site-specific phosphorylated antibodies against Raptor (Ser792, catalog no. 2280/2083), S6K1 (Thr389, catalog no. 9202/9205), eEF2 (Thr56, catalog no. 2332/2331), and G protein $\beta$ subunit-like (GßL, catalog no. 3274) were purchased from Cell Signaling Technology Inc., (Danvers, MA). The $\beta$-CN antibody (catalog no. orb18512) was purchased from Biorbyt Ltd. (Cambridge, UK) and the antibody against $\beta$-actin (catalog no. ab8226) used as a loading control was purchased from Abcam (Shanghai Trading Co. Ltd.).

\section{Cell Culture}

The CMEC-H cells were established as described in our previous work (Hu et al., 2016). The CMEC-H cells exhibit the typical cobblestone morphology characteristic and propagation in long-term culture. These cells can express stem cell markers and can be induced to differentiate and synthesize milk proteins. The CMEC-H cells were cultured in 10-cm dishes (catalog no. 172958, Thermo Scientific, Rockford, IL) at $38^{\circ} \mathrm{C}$ with $5 \% \mathrm{CO}_{2}$. Dulbecco's modified Eagle's medium (DMEM)/Ham's F-12 (diluted 1:1, catalog no. 1439945/1491066, Invitrogen Trading Co. Ltd., Shanghai, China) containing $10 \%$ fetal bovine serum (Invitrogen Trading Co. Ltd.) and $100 \mu \mathrm{g} / \mathrm{mL}$ of Penicillin-Streptomycin Solution (catalog no. C0222, Beyotime Institute of Biotechnology, Jiangsu, China) was used as the basal growth medium until they reached $80 \%$ confluence and then passaged with $0.25 \%$ trpysin- $0.02 \%$ EDTA (catalog no. C0203, Beyotime Institute of Biotechnology).

Experiment 1. Individual Effects of the EAA on Cell Proliferation. The 3-(4,5-dimethylthiazol2-yl)-2,5-diphenyl tetrazolium bromide (MTT) method was used to evaluate the effect of varying concentrations of His, Lys, Met, and Leu on the ratio of relative growth rate of the CMEC-H cells (Nan et al., 2014; Gao et al., 2015). Cells were seeded in 96-well microplates by adding a $100 \mu \mathrm{L} /$ well of a suspension of 5,000 cells in DMEM/F-12 containing 10\% fetal bovine serum and were cultured for $24 \mathrm{~h}$. Afterward, the cells were serum-starved overnight and then were cultured in 200 $\mu \mathrm{L}$ of medium devoid of all AA (-AAA; catalog no. ME14034L1, Invitrogen Trading Co. Ltd.) or in -AA medium supplemented with all AA $(+\mathbf{A A})$ or with varying concentrations of His (at $0,0.15,0.6,1.2,4.8$, 9.6, 19.2, 28.8, and $43.2 \mathrm{mM}$ ), Lys (at 0, 0.5, 2, 4, 8, 16, 24, and $36 \mathrm{mM}$ ), Met (at 0, 0.12, 0.72, 1.44, 4.32, 8.64, 17.28, 25.92, and $38.88 \mathrm{mM}$ ), and Leu (at 0, 0.45, $1.35,5.4,10.8,21.6,32.4$, and $48.6 \mathrm{mM}$ ) for $12 \mathrm{~h}$. Each concentration was tested in 6 independent wells and the design was considered to be completely randomized. After the indicated time, the AA-containing medium 
was removed and $100 \mu \mathrm{L}$ of $0.5 \mathrm{mg} / \mathrm{mL}$ of MTT (Amresco, Solon, $\mathrm{OH}$ ) was added and incubated for $4 \mathrm{~h}$. The formazan crystals were solubilized in $150 \mu \mathrm{L}$ of dimethyl sulfoxide (catalog no. D 4045-1L, Sigma USA, St. Louis, MO). The plates were gently shaken for 3 min so that complete dissolution was achieved. The absorbance was measured at $450 \mathrm{~nm}$ using an automatic ELISA reader (Calvert et al., 2005). The results were presented as the relative growth rate of the AA-treated wells respective to that for the negative control ( $-\mathrm{AA})$ cells.

Experiment 2. Individual Effects of EAA on $\boldsymbol{\beta}-\boldsymbol{C N}$ Expression. This experiment was designed to characterize the optimal dose of each tested EAA that achieved the maximum $\beta$-CN expression in the CMEC$\mathrm{H}$ cells. The optimal range of the concentrations for each EAA (His, Lys, Met, and Leu) was based on the results from experiment 1 (i.e., the cell growth). The differentiated CMEC-H cells were incubated in the specific medium supplemented with His, Lys, Met, and Leu for $6 \mathrm{~h}$ at the indicated concentrations. There were 3 replicates per treatment in a completely randomized design. The expression of $\beta$-CN was determined by western blot (see below). A specific medium without any AA was used as the negative control ( $-\mathrm{AA})$. The DMEM/F-12 medium was used as the positive control ( $+\mathrm{AA}$; the concentrations of His, Lys, Met, and Leu in the DMEM/F-12 medium were $0.15,0.5,0.22$, and 0.45 $\mathrm{m} M$, respectively).

Experiment 3. Optimum Combination of the EAA for $\beta-C N$ Expression by Response Surface Methodology. To optimize the expression of $\beta-\mathrm{CN}$ and verify the synergy of tested EAA, a central composite experimental design (Myers and Montgomery, 2002) was developed with 4 variables at each of 5 levels (Table 1 ) using Design-Expert Software (version 8.0.6) from StatEase Inc. (Minneapolis, MN). The boundary levels for each individual AA concentration were as follows: His (0.15-9.60 mM), Lys (0.5-16.0 $\mathrm{mM})$, Met (0.12-4.32 $\mathrm{m} M)$, and Leu $(0.45-10.80 \mathrm{mM})$. Table 2 shows the 28 combinations of the $4 \mathrm{EAA}$ in the actual experiment. The differentiated CMEC-H cells were incubated in the specific medium supplemented with a combination of the 4 EAA (His, Lys, Met, and Leu) for $6 \mathrm{~h}$ at the indicated concentrations. Each of the 28 treatments was replicated 3 times in a completely randomized design, and the $\beta$-CN expression was determined by western blot (see below).

Experiment 4. Effects of the Optimized EAA on $\beta-C N$ Expression and mTOR Pathway. This experiment used a completely randomized design with 7 treatments. The CMEC-H cells were treated with the medium without any AA (-AA), with medium con- taining all of the AA $(+\mathrm{AA})$ or with medium containing His $(0.15 \mathrm{~m} M)$, Lys $(0.5 \mathrm{~m} M)$, Met $(0.12 \mathrm{~m} M)$, and Leu $(10.8 \mathrm{mM})$ individually or a combination of these 4 EAA $(5.47 \mathrm{~m} M$ of His, $7.48 \mathrm{~m} M$ of Lys, $1.17 \mathrm{mM}$ of Met, and $8.21 \mathrm{~m} M$ of Leu). There were 3 replicates per treatment. The expression of proteins was determined by western blot (see below).

\section{Western Blot Analysis}

The cell samples were lysed by scraping cells into ice-cold radio-immunoprecipitation assay buffer (cata$\log$ no. P0013, Beyotime Institute of Biotechnology) containing $1 \mathrm{~m} M$ of phenylmethylsulfonyl fluoride, and $1 \%$ (vol:vol) of protease and phosphatase inhibitor cocktail (catalog no. 78430, Thermo Scientific). The obtained cell lysates were centrifuged at $2,000 \times g$ for $3 \mathrm{~min}$ at $4^{\circ} \mathrm{C}$ and the supernatant was transferred to a new tube. The protein concentrations of the samples were determined by the bicinchoninic acid assay kits (catalog no. P0010S, Beyotime Institute of Biotechnology). The lysates (30 $\mu \mathrm{g}$ of protein) were loaded onto gels and were separated by $10 \%$ SDS-PAGE and blotted onto polyvinylidene difluoride transfer membranes (0.45 and $0.2 \mu M$ immobilon-P, catalog no. IPVH00010 and ISEQ00010, Millipore, Billerica, MA). The membranes were blocked for $1 \mathrm{~h}$ (blot-PO Buffer, catalog no. WBAVDP001, Millipore) and were incubated overnight at $4^{\circ} \mathrm{C}$ with primary antibodies (appropriately diluted 1:1,000 in PBS) against total and site-specific phosphorylated mTOR (Ser $\left.{ }^{2481}\right), \quad 4 \mathrm{EBP} 1\left(\mathrm{Thr}^{37}\right)$, RPS6 $\left(\mathrm{Ser}^{235 / 236}\right)$, eIF2 $\alpha\left(\mathrm{Ser}^{51}\right)$, Raptor $\left(\mathrm{Ser}^{792}\right)$, S6K1 $\left(\mathrm{Thr}^{389}\right)$, eEF2 $\left(\mathrm{Thr}^{56}\right)$, and G $\beta \mathrm{L}$. The $\beta$-CN level was determined by its antibodies (1:500). The blots were washed 3 times with TBST and then incubated with the secondary antibody (anti-rabbit IgG, catalog no. A9169, Sigma; anti-goat IgG, catalog no. AP106P, Millipore; anti-mouse IgG, catalog no. A9044, Sigma) diluted at 1:3,000 in PBS.

The immunoreactive bands were visualized using the Pierce ECL Western Blot Substrate (catalog no. 32106, Thermo Scientific) according to the manufacturer's

Table 1. Coded values and the EAA concentrations $(\mathrm{m} M)$ in the central composite experimental design

\begin{tabular}{lcrcr}
\hline Coded value & His $(\mathrm{m} M)$ & Lys $(\mathrm{m} M)$ & Met $(\mathrm{m} M)$ & Leu $(\mathrm{m} M)$ \\
\hline-2 & 0.1500 & 0.5000 & 0.1200 & 0.4500 \\
-1 & 2.5125 & 4.3750 & 1.1700 & 3.0375 \\
0 & 4.8750 & 8.2500 & 2.2200 & 5.6250 \\
1 & 7.2375 & 12.1250 & 3.2700 & 8.2125 \\
2 & 9.6000 & 16.0000 & 4.3200 & 10.8000 \\
\hline
\end{tabular}


instructions and exposed to x-ray film (X-OMAT BT, Kodak China Investment Co. Ltd., Beijing, China). The protein band densities were assayed by the Image J2x 2.1.4.7 Analyzer (Rawak Software Inc., Stuttgart, Germany). Band densities of EAA-supplementation treatments were normalized to that of negative control treatment.

\section{Statistical Analysis}

Data from experiments 1,2 , and 4 were analyzed using the GLM procedure in SAS software (version 9.2) from SAS Institute Inc. (Cary, NC). For experiment 1, the data for each EAA concentration series were analyzed separately (i.e., for His, the series of treatments $0,0.15,0.6,1.2,4.8,9.6,19.2,28.8$, and 43.2 $\mathrm{m} M$ were analyzed as a completely randomized design, with 6 independent wells as experimental units in each treatment). This same approach was used for the data from the Lys series of concentrations, as well as Met and Leu, yielding 4 separate analyses. The model for each EAA concentration series in experiment 1 was as follows:

$$
Y_{i j}=\mu+t_{i}+e_{i j},
$$

where $Y_{i j}$ represents an observation on the relative growth rate of the $j$ replicate in the $i$ treatment; $\mu$ is the coefficient; $t_{i}$ is the effect of the $i$ treatment ( $i=1$ to 9 , e.g., His at levels $0,0.15,0.6,1.2,4.8,9.6,19.2,28.8$, and $43.2 \mathrm{mM}$ ), which was considered a fixed effect; and $e_{i j}$ is the random error deviation of the $j$ replicate in the $i$ treatment. The error deviations were assumed to be normally distributed, with homogeneous variances across all treatments for each variable. Diagnostic tests to evaluate these assumptions were Levene's test for homogeneity of variance in the GLM procedure and the test for normality in the Univariate procedure (SAS Institute Inc.). Residuals for all 4 analyses showed homogeneity of variance across treatments. The normality of residuals had significant $(P<0.05)$ departures from normality (Shapiro-Wilks test) for the His series of treatment as well as the Met series of treatments. This may reduce our confidence in the conclusion for these 2 analyses.

For experiment 2, the data for each EAA series were again analyzed separately, as was done for experiment

Table 2. Coded values of EAA in the central composite experimental design and experimental data of $\beta$-CN expression $^{1}$

\begin{tabular}{|c|c|c|c|c|c|}
\hline Treatment (i) & $X_{1}$ (His) & $X_{2}(\mathrm{Lys})$ & $X_{3}$ (Met) & $X_{4}(\mathrm{Leu})$ & $Y_{i}$ mean $(\beta-\mathrm{CN})$ \\
\hline 1 & -1 & -1 & -1 & -1 & 2.41 \\
\hline 2 & 1 & -1 & -1 & -1 & 4.25 \\
\hline 3 & -1 & 1 & -1 & -1 & 3.39 \\
\hline 4 & 1 & 1 & -1 & -1 & 3.00 \\
\hline 5 & -1 & -1 & 1 & -1 & 4.39 \\
\hline 6 & 1 & -1 & 1 & -1 & 4.62 \\
\hline 7 & -1 & 1 & 1 & -1 & 2.93 \\
\hline 8 & 1 & 1 & 1 & -1 & 6.26 \\
\hline 9 & -1 & -1 & -1 & 1 & 9.00 \\
\hline 10 & 1 & -1 & -1 & 1 & 6.32 \\
\hline 11 & -1 & 1 & -1 & 1 & 5.05 \\
\hline 12 & 1 & 1 & -1 & 1 & 7.43 \\
\hline 13 & -1 & -1 & 1 & 1 & 3.67 \\
\hline 14 & 1 & 1 & -1 & 1 & 4.38 \\
\hline 15 & 1 & -1 & 1 & -1 & 3.91 \\
\hline 16 & 1 & 1 & 1 & 1 & 3.40 \\
\hline 17 & -2 & 0 & 0 & 0 & 2.12 \\
\hline 18 & 2 & 0 & 0 & 0 & 3.10 \\
\hline 19 & 0 & -2 & 0 & 0 & 3.25 \\
\hline 20 & 0 & 2 & 0 & 0 & 2.85 \\
\hline 21 & 0 & 0 & -2 & 0 & 4.39 \\
\hline 22 & 0 & 0 & 2 & 0 & 4.64 \\
\hline 23 & 0 & 0 & 0 & -2 & 4.43 \\
\hline 24 & 0 & 0 & 0 & 2 & 7.00 \\
\hline 25 & 0 & 0 & 0 & 0 & 5.76 \\
\hline 26 & 0 & 0 & 0 & 0 & 5.45 \\
\hline 27 & 0 & 0 & 0 & 0 & 4.95 \\
\hline 28 & 0 & 0 & 0 & 0 & 4.97 \\
\hline
\end{tabular}

${ }^{1} X_{1}=$ coded concentration of His; $X_{2}=$ coded concentration of Lys; $X_{3}=$ coded concentration of Met; $X_{4}=$ coded concentration of Leu; $Y_{i}$ represents an observation on the $\beta$-CN fold change relative to the control (AA) treatment for the $i$ th treatment. 
1 , yielding 4 separate analyses. The model for experiment 2 was as follows:

$$
Y_{i j}=\mu+t_{i}+e_{i j},
$$

where $Y_{i j}$ represents an observation on the $\beta$-CN fold change relative to the control $(-\mathrm{AA})$ treatment for the $j$ th replicate in the $i$ th treatment; $t_{i}$ is the effect of the $i$ th treatment, which was considered a fixed effect; and $e_{i j}$ is the random error deviation of the $j$ th replicate in the $i$ th treatment. Assumptions and diagnostic tests to evaluate these assumptions were the same as those described above for experiment 1. Diagnostic tests to evaluate assumptions relating to the residuals in these 4 separate analyses showed that residuals were homogeneous across treatments and that the residuals were normally distributed.

In experiment 4, seven treatments consisted of the individual EAA or a combination of EAA. The variables measured here included $\beta$-CN fold change relative to the control (-AA), mTOR, Raptor, G $\beta \mathrm{L}$, S6K1, 4EBP1, RPS6, eEF2, and eIF2 $\alpha$. The model for each of these variables in experiment 4 was as follows:

$$
Y_{i j}=\mu+t_{i}+e_{i j}
$$

where $Y_{i j}$ represents an observation of the $\beta$-CN fold change (for example) for the $j$ th replicate in the $i$ th treatment; $t_{i}$ is the effect of the $i$ th treatment, which was considered a fixed effect; and $e_{i j}$ is the random error deviation of the $j$ th replicate in the ith treatment. Assumptions and diagnostic tests to evaluate these assumptions were the same as those described above for experiment 1 . Homogeneity of variance for residuals across treatments was found for all variables, and all variables demonstrated normality of residuals except for S6K1 (Shapiro-Wilks $P=0.0426$ ). Thus, our confidence in the conclusions for this variable may be reduced as a result.

For experiments 1, 2, and 4, treatment means were compared using the Tukey's test for post-hoc multiple comparisons of treatment means. Differences between experimental groups were considered significant at $P$ $<0.05$.

$\beta$-Casein data from the response surface methodology (RSM) experimental design (experiment 3) were analyzed using a regression analysis (Design-Expert, version 8.0.6, from Stat-Ease Inc.), and the same program was used for plotting the response surface containing linear and quadratic effects of the 4 EAA as well as effects due to their interaction. The stepwise procedure for model simplification was based on the process de- scribed by Draper and Smith (1998), starting with the maximal model (all linear, quadratic, and cross-product terms). This maximal model was as follows:

$$
\begin{aligned}
Y_{i}= & b_{0}+b_{1} X_{1 i}+b_{2} X_{2 i}+b_{3} X_{3 i}+b_{4} X_{4 i}+b_{5} X_{1 i} X_{2 i} \\
& +b_{6} X_{1 i} X_{3 i}+b_{7} X_{1 i} X_{4 i}+b_{8} X_{2 i} X_{3 i}+b_{9} X_{2 i} X_{4 i}+b_{10} X_{3 i} X_{4 i} \\
& +b_{11} X_{1 i}^{2}+b_{12} X_{2 i}^{2}+b_{13} X_{3 i}^{2}+b_{14} X_{4 i}^{2}+e_{i},
\end{aligned}
$$

where $Y_{i}$ is the mean $\beta$-CN expression of the 3 replicates in the $i$ th treatment ( $i=1$ to 28 , see Table 2 ), $X_{1 i}$ is the coded value representing the level of His in the $i$ th treatment, $X_{2 i}$ is the coded value representing the level of Lys, $X_{3 i}$ is the coded value representing the level of Met, and $X_{4 i}$ is the coded value representing the level of Leu. Cross-product and quadratic terms of the $4 \mathrm{AA}$, and the regression coefficients $\left(b_{0}\right.$ to $\left.b_{14}\right)$ representing the effect size of each of these factors on $\beta-\mathrm{CN}$ expression were also presented in the model. The error deviation due to the $i$ th treatment group is denoted as $e_{i}$. Following Draper and Smith (1998), this model was simplified by removing the least significant terms first, starting with the highest order interactions, then the quadratic terms, and finally the linear terms. The removal of the terms was carried out one term at a time, and the analysis was rerun each time, until all terms remaining in the model were significant $(P<0.05)$, with an exception according to Draper and Smith (1998). They suggested that when interactions or quadratic terms were found to be significant, their linear terms should be retained in the model even when not significant. For example, if $X_{1 i}^{2}$ was found to be significant $(P<0.05)$ then its linear term $\left(X_{1 i}\right)$ would be retained in the model whether or not it is significant. The resulting model was then used to study the optimum production of $\beta-\mathrm{CN}$ due to each of the AA that was studied using Design-Expert software.

\section{RESULTS}

\section{Experiment 1. Cell Growth Due to Varying Individual $A A$}

The dose-response curves of the effect of His, Lys, Met, and Leu on CMEC-H cells for $12 \mathrm{~h}$ treatment are reported in Figure 1. Cell proliferation declined with increasing EAA concentrations. In particular, the number of viable cells reach a maximum at $1.20 \mathrm{~m} M$ of His, $2.00 \mathrm{~m} M$ of Lys, $1.44 \mathrm{~m} M$ of Met, and $1.35 \mathrm{~m} M$ of Leu $(P<0.01)$. Using as a criterion proliferation $\geq 110 \%$ compared with the negative control, we selected 4 doses for each EAA for the subsequent experiments (i.e., 0.15 to $9.60 \mathrm{~m} M$ for His, 0.5 to $16.0 \mathrm{~m} M$ for Lys, 0.12 to 8.64 $\mathrm{m} M$ for Met, and 0.45 to $10.80 \mathrm{~m} M$ for Leu). 

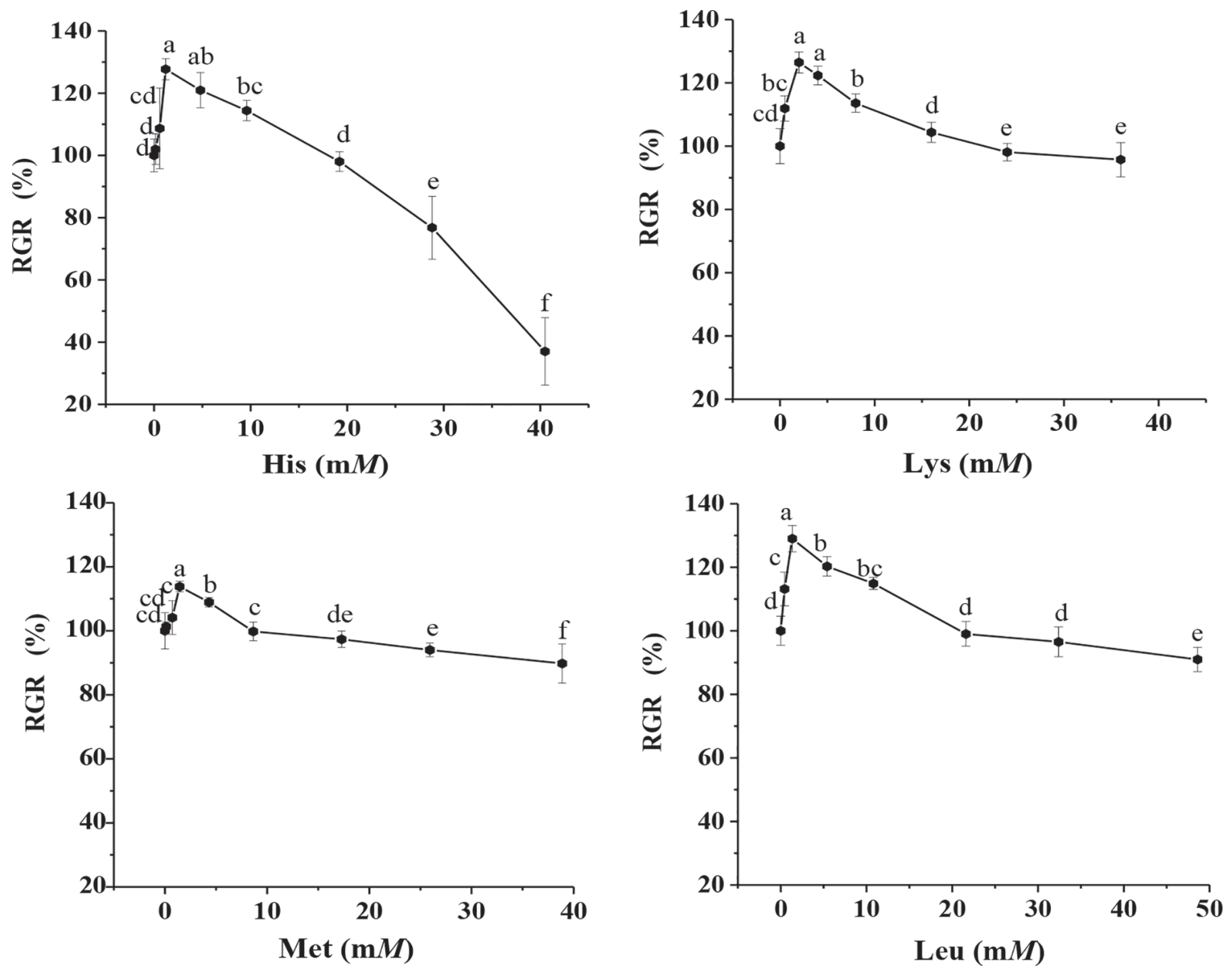

Figure 1. Experiment 1: effect of EAA on the immortalized bovine mammary epithelial cell line (CMEC-H) relative growth rate (RGR, \%). Cells were cultured with the indicated concentration $(\mathrm{m} M)$ of His, Lys, Met, and Leu for $12 \mathrm{~h}$. Data (means $\pm \mathrm{SEM}$; $\mathrm{n}=6 \mathrm{per}$ group) are expressed as a percentage of the supplemented EAA relative to that in the medium without AA ( - AA). Means with different letters are significantly different $(P<0.05)$ using Tukey's multiple comparison procedure.

\section{Experiment 2. Effect of the Individual EAA on $\beta-C N$ Expression}

The dose-dependent effects of the individual EAA His, Lys, Met, and Leu on $\beta-\mathrm{CN}$ expression are presented in Figure 2. Compared with the positive control, the $\beta$-CN expression decreased linearly as the concentration of His, Lys, and Met increased. However, the $\beta-\mathrm{CN}$ expression increased linearly as the concentration of Leu increased. With the exception of His at $9.6 \mathrm{~m} M$, His, Lys, Met, and Leu notably stimulated $\beta-\mathrm{CN}$ expression relative to the control (Figure 2) and $\beta$-CN had the highest expression at $0.15 \mathrm{~m} M$ of His,
$0.5 \mathrm{~m} M$ of Lys, $0.12 \mathrm{~m} M$ of Met, and $10.8 \mathrm{~m} M$ of Leu, respectively.

\section{Experiment 3. The Factorial Effects of His, Lys, Met, and Leu on $\beta-C N$ Expression}

The RSM in $\beta-\mathrm{CN}$ to various levels and combinations of the EAA is shown in Supplemental Figure S1 (https://doi.org/10.3168/jds.2016-10729) and Table 2 and the regression analysis for the RSM results is shown in Table 3. To identify the optimal conditions, the RSM model for the expression of $\beta-\mathrm{CN}$ was obtained as a second-order prediction equation. The optimum condi- 
A
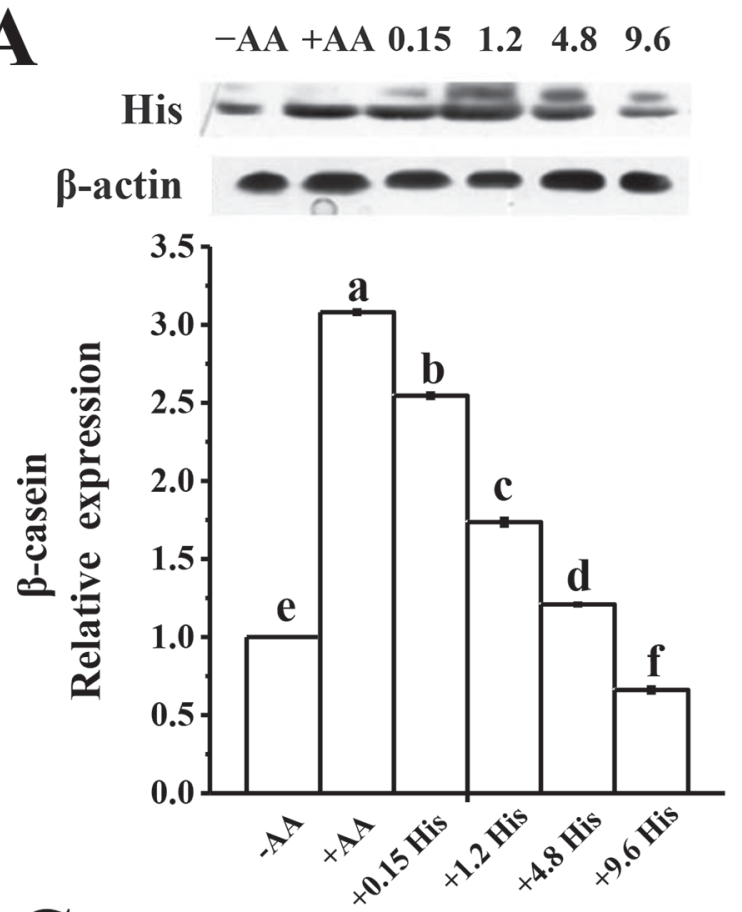

$\mathcal{C}$

$\begin{array}{llllll}-\mathrm{AA} & +\mathrm{AA} & 0.12 & 0.72 & 1.44 & 4.32\end{array}$
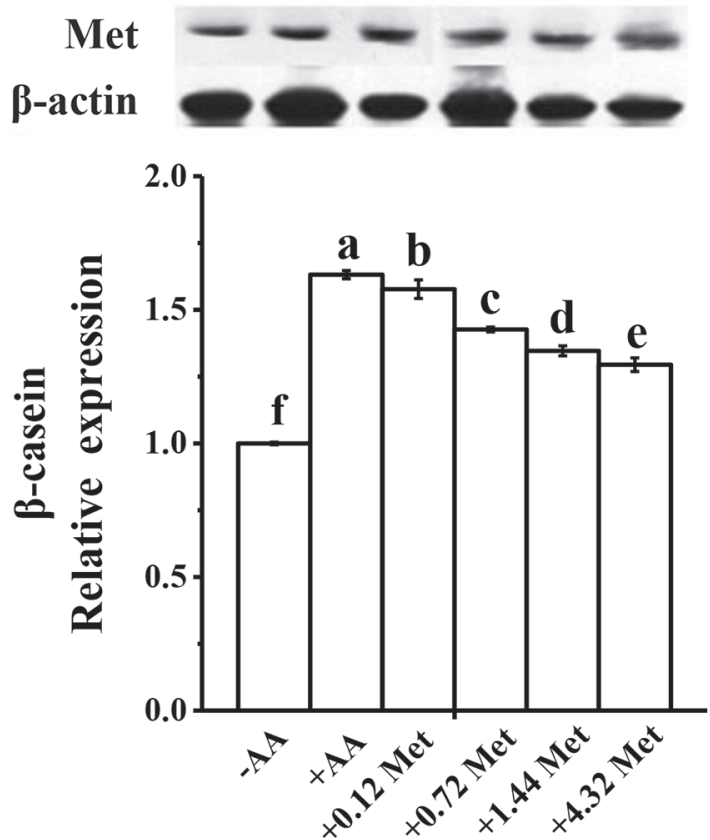

B $\begin{array}{llllll}-\mathrm{AA} & +\mathrm{AA} & 0.5 & 2 & 8 & 16\end{array}$

Lys $\beta$-actin

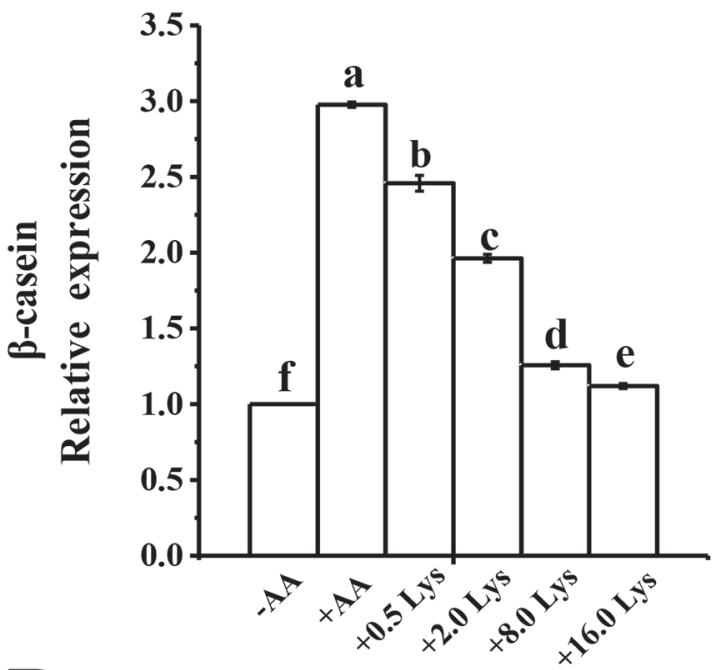

D

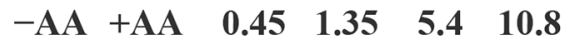

Leu

$\beta$-actin

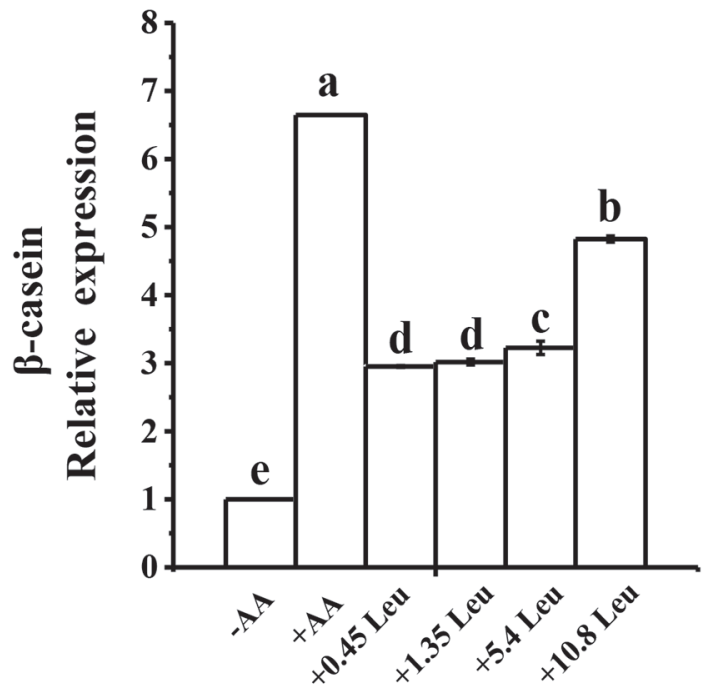

Figure 2. Experiment 2: His (A), Lys (B), Met (C), and Leu (D) have diverse effects on $\beta$-CN expression in the immortalized bovine mammary epithelial cell line (CMEC-H). The His (A), Lys (B), Met (C), and Leu (D) were supplemented for $6 \mathrm{~h}$ at the indicated concentrations $(\mathrm{m} M)$. $\beta$-Casein levels were determined by immunoblot analysis. Numbers above the lanes refer to the level of the supplemented indicated AA relative to that in the medium without AA (-AA, used as the negative control). $\beta$-Actin was assessed as a loading control. A representative blot is shown. In all panels, data represent the means \pm SEM ( $n=3$ per group). Means marked with different letters are significantly different $(P<0.05)$ using Tukey's multiple comparison procedure. $+\mathrm{AA}=$ in the medium with all AA. 
Table 3. Summary of final regression model relating $\beta$-CN production by the immortalized bovine mammary epithelial cell line (CMEC-H) cells to varying levels of His, Lys, Met, and Leu

\begin{tabular}{lccrcc}
\hline Source & Coefficient estimate & $\mathrm{SE}$ & $F$-value & $P$-value & $\mathrm{R}^{2}$ \\
\hline Model & & & 6.98 & 0.0003 & 0.71 \\
Intercept & 5.45 & 0.32 & & & \\
$X_{1}$ (His) & 0.29 & 0.20 & 1.95 & 0.1774 & \\
$X_{2}$ (Lys) & -0.19 & 0.20 & 0.83 & 0.3739 & \\
$X_{3}$ (Met) & -0.28 & 0.20 & 1.91 & 0.1823 & \\
$X_{4}$ (Leu) & 0.71 & 0.20 & 12.04 & 0.0024 & \\
$X_{3} X_{4}$ & -1.10 & 0.25 & 19.22 & 0.0003 & \\
$X_{1}{ }^{2}$ & -0.58 & 0.19 & 9.03 & 0.0070 & \\
$X_{2}{ }^{2}$ & -0.47 & 0.19 & 5.94 & 0.0242 & \\
\hline Source & Sum of squares & Mean square & df & \multirow{2}{*}{$P$-value } & \\
\hline Residual & 20.12 & 1.01 & 20 & & \\
Lack of fit & 19.66 & 1.16 & 17 & 0.0614 & \\
Pure error & 0.46 & & & & \\
\hline
\end{tabular}

tions for $\beta$-CN expression were observed at $5.47 \mathrm{mM}$ of His, $7.48 \mathrm{~m} M$ of Lys, $1.17 \mathrm{~m} M$ of Met, and $8.21 \mathrm{~m} M$ of Leu (His:Lys:Met:Leu $=5: 6: 1: 7)$. The ANOVA for the RSM model gave an $F$-value of $6.98(P<0.05)$ and an $\mathrm{R}^{2}$ value of 0.71 . The relative importance of the various $\mathrm{AA}$ in their effects on $\beta$-CN can be seen in Table 3, where the linear effect of Leu, for example, ranked high in importance $(F=12.04, P=0.0024)$, and its interaction effect with Met also was important $(F=19.22, P$ $=0.0003)$. In addition, the quadratic effects of His $(F$ $=9.03, P=0.0070)$ and Met $(F=5.94, P=0.0242)$ also had significant relationships with $\beta$-CN expression.

The optimum response levels are shown in Figure 3. A significant quadratic response $(P<0.05)$ was observed in $\beta$-CN to His (Figure 3A) and Lys (Figure $3 \mathrm{~B})$. These responses were independent of each other as there was no significant interaction $(P>0.05)$. A significant interaction was observed between Met and Leu $(P=0.0003)$, where a higher response in $\beta$-CN was identified with higher levels of Leu and lower levels of Met (Leu >8.2125 and Met <1.17) under experimental condition (Figure 3C). This suggests that an optimum combination of these 2 AA may lie outside the range of levels explored in this experiment.

\section{Experiment 4. Effects of the Optimized EAA on $\beta$-Casein Expression}

The results of this experiment are given in Figure 4. Compared with the negative control, the addition of the optimal conditions for casein expression significantly increased the expression of $\beta$-CN. The order of the expression level of $\beta-\mathrm{CN}$ in our study is as follows: with all of the AA (+AA) $>$ AA as optimal mix (Mix) $>$ individual AA (Leu $>$ Lys $>$ His $>$ Met) $>$ without any AA (-AA). As observed in Figure 4, the optimal combination of 4 EAA (mix) significantly increased the $\beta$-CN expression to 16 times compared with $-\mathrm{AA}$. These observations demonstrate that $\beta$-CN expression with the optimal mixture of 4 EAA was less than the positive control (i.e., media with all AA, +AA) and $\beta-\mathrm{CN}$ expression when EAA were in the optimal mix was always higher than its expression with individual EAA (Figures 4A and 4B).

\section{Experiment 4. Effects of Optimized EAA on mTORC1}

When His, Lys, Met, and Leu were added either individually or as an optimal mix, in comparison with the negative control group the expression of the phosphorylation $(\mathbf{P})$ of mTOR $\left(\mathrm{Ser}^{2481}\right)$, P-Raptor $\left(\mathrm{Ser}^{792}\right)$, and G $\beta \mathrm{L}$ was increased in the CMEC-H cells. All of these responses were maximized at the optimal EAA mix (Figures 5A and 5B).

\section{Experiment 4. Effects of Optimized EAA on mTOR Downstream Signaling Proteins}

The results shown in Figures $6 \mathrm{~A}$ to $6 \mathrm{D}$ demonstrated that P-S6K1 $\left(\mathrm{Thr}^{389}\right.$ ) and P-RPS6 $\left(\mathrm{Ser}^{235 / 236}\right.$ ) levels increased with supplementation of His, Lys, Met, and Leu as an optimal mix or alone. Addition of Lys, Met, or Leu to the medium devoid of all AA inhibited P4EBP1 $\left(\mathrm{Thr}^{37}\right)$ in CMEC-H compared with the negative control (i.e., medium without AA, -AA), whereas the combination of His, Lys, Met, and Leu, or His alone increased P-4EBP1 ( $\mathrm{Thr}^{37}$; Figure 6B). Our study indicated that with the addition of Met, P-eIF2 $\alpha\left(\mathrm{Ser}^{51}\right)$ level was reduced $(P<0.05)$. The optimal combination of EAA enhanced the P-eIF2 $\alpha\left(\mathrm{Ser}^{51}\right)$ level (Figure 

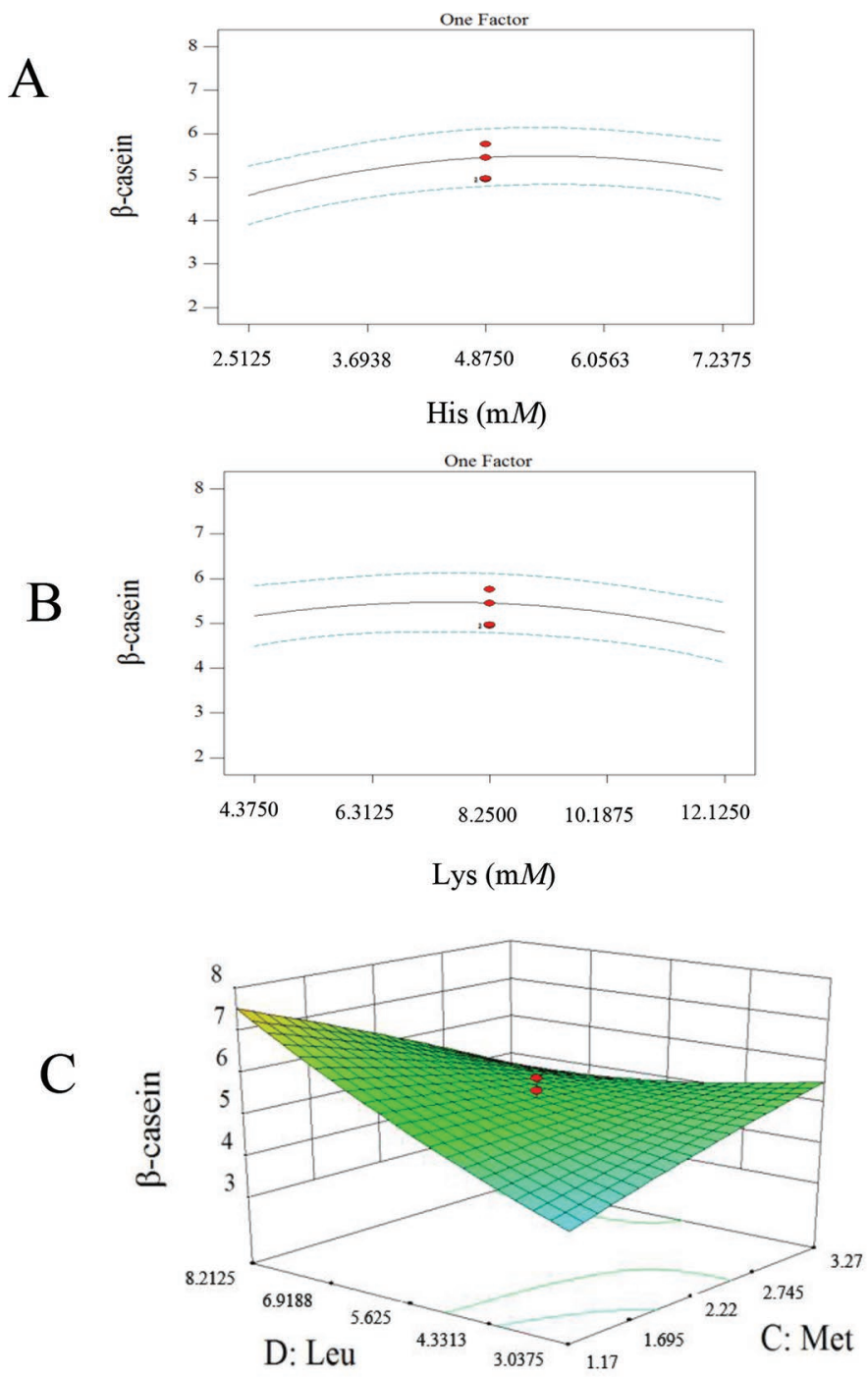

Figure 3. Experiment 3: graphs showing results of response surface methodology analysis relating $\beta-\mathrm{CN}$ to 4 EAA. The EAA effects shown here are from a model containing only significant $(P<0.05)$ effects. The levels of EAA shown in the graphs are coded levels, see Table 1. (A) Quadratic response of $\beta-\mathrm{CN}$ to His. (B) Quadratic response of $\beta-\mathrm{CN}$ to Lys. (C) Interaction of Leu and Met in effects on $\beta$-CN. Color version available online.

$6 \mathrm{D})$. The optimal mixture of the 4 EAA or the addition of single EAA increased P-eEF2 $\left(\mathrm{Thr}^{56}\right)$ level in the CMEC-H cells (Figure 6D).

\section{DISCUSSION}

$\beta$-Casein forms a high proportion of milk protein; therefore, factors that affect $\beta$-CN production have a large effect on milk protein productivity of dairy cows (Davies and Law, 1983). Amino acids are the main factors contributing milk protein synthesis, with Met and
A

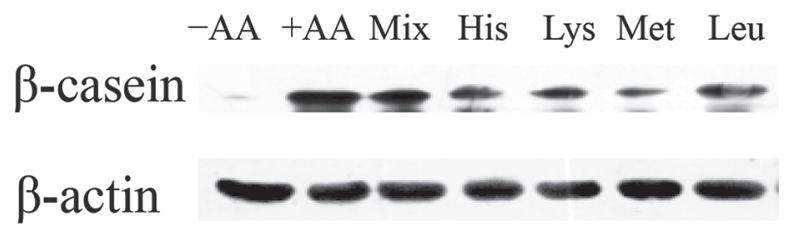

B

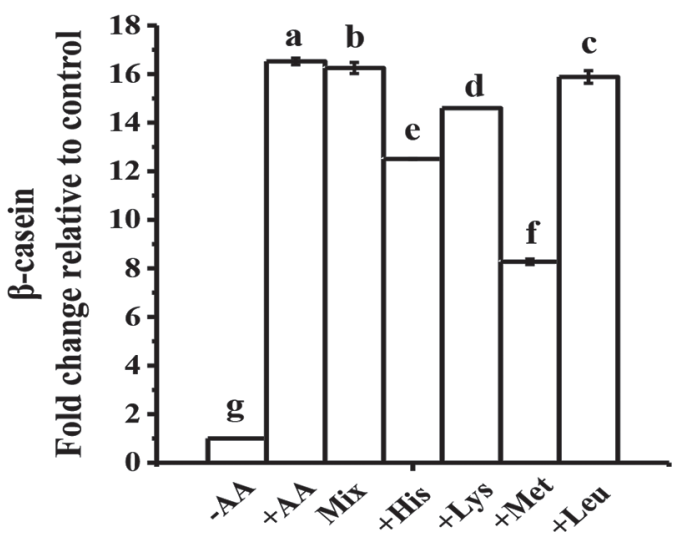

Figure 4. Experiment 4: effects of His, Lys, Met, and Leu added in combination or alone on $\beta-\mathrm{CN}$ in the immortalized bovine mammary epithelial cell line (CMEC-H). (A) His, Lys, Met, and Leu or an optimal mix were supplemented for $6 \mathrm{~h}$ at the indicated concentrations (His $=0.15 \mathrm{~m} M$, Lys $=0.5 \mathrm{~m} M$, Met $=0.12 \mathrm{~m} M$, and Leu $=0.45 \mathrm{~m} M$ or their combination). $\beta$-Casein levels were determined by immunoblot analysis. The labels above the lanes refer to the EAA treatment. (A) A representative blot of signals obtained from the casein immunoblot. $\beta$-actin was assessed as a loading control. (B) Comparison of $\beta$-CN produced as a result of the various EAA treatments. Data represent the means \pm SEM ( $n=3$ per group). Means marked with different letters are significantly different $(P<0.05)$ using Tukey's multiple comparison procedure. $+\mathrm{AA}=$ in the medium with all $\mathrm{AA} .-\mathrm{AA}=$ in the medium without AA was used as the negative control. Mix $=$ the 4 EAA as an optimal mix.

Lys being the important EAA in the bovine mammary gland (Nan et al., 2014). In addition to Met and Lys, several other EAA (i.e., Leu and His) are important (Kim et al., 2001; Korhonen et al., 2002; Hanigan et al., 2002). Some studies have indicated that not only the content of EAA in the diet, but also the ratio of EAA is very important for milk protein synthesis (Prizant and Barash, 2008; Arriola Apelo et al., 2014b; Nan et al., 2014). Response surface methodology is a novel method and a powerful mathematical technique for evaluating the relationship between variables and their response (Myers and Montgomery, 2002; Zhou et al., 2015). Essentially this method permits the evaluation of multiple factors, which may effectively overcome the drawback of the classic "one-factor-at-a-time" or "full-factors" approach. In the present study, RSM was used to evaluate the optimal ratio of the $4 \mathrm{EAA}$ for $\beta-\mathrm{CN}$ expression 
and the potential molecular mechanism on the mTOR signaling pathway.

The regulation of cell growth and protein biosynthesis triggered by the mTORC1 response to EAA has been reported in CMEC (Mercier and Vilotte, 1993; Nan et al., 2014; Gao et al., 2015), pig small intestinal epithelial cells (Wang et al., 2015), and pig skeletal muscle cells (Wang et al., 2007). Therefore, it was not surprising, therefore, to observe the increase in cell proliferation induced by His, Lys, Met, and Leu, and as previous studies demonstrated, that the number of CMEC was a determining factor for casein expression (Nan et al., 2014; Gao et al., 2015). In agreement with previous studies, results from our study suggest that CMEC-H proliferation is dependent on the dose of supplemental EAA, and cell proliferation is reduced at higher doses (19.2-40.5 $\mathrm{m} M$ of His, 24-36 $\mathrm{m} M$ of Lys, $8.64-38.8 \mathrm{mM}$ of Met, and 21.6-48.6 $\mathrm{mM}$ of Leu). Thus the decrease in number of viable cells may be a consequence of cytotoxicity (Sestili et al., 1995).

The synthesis of $\beta$-CN increases as a function of the AA concentration in CMEC (Bionaz et al., 2012). Some results focusing on the role of high single AA concentrations on transport and catabolism of other AA and the overall effect of such an antagonism on integrated mTORC1 activity. Prizant and Barash (2008) showed

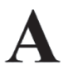

B
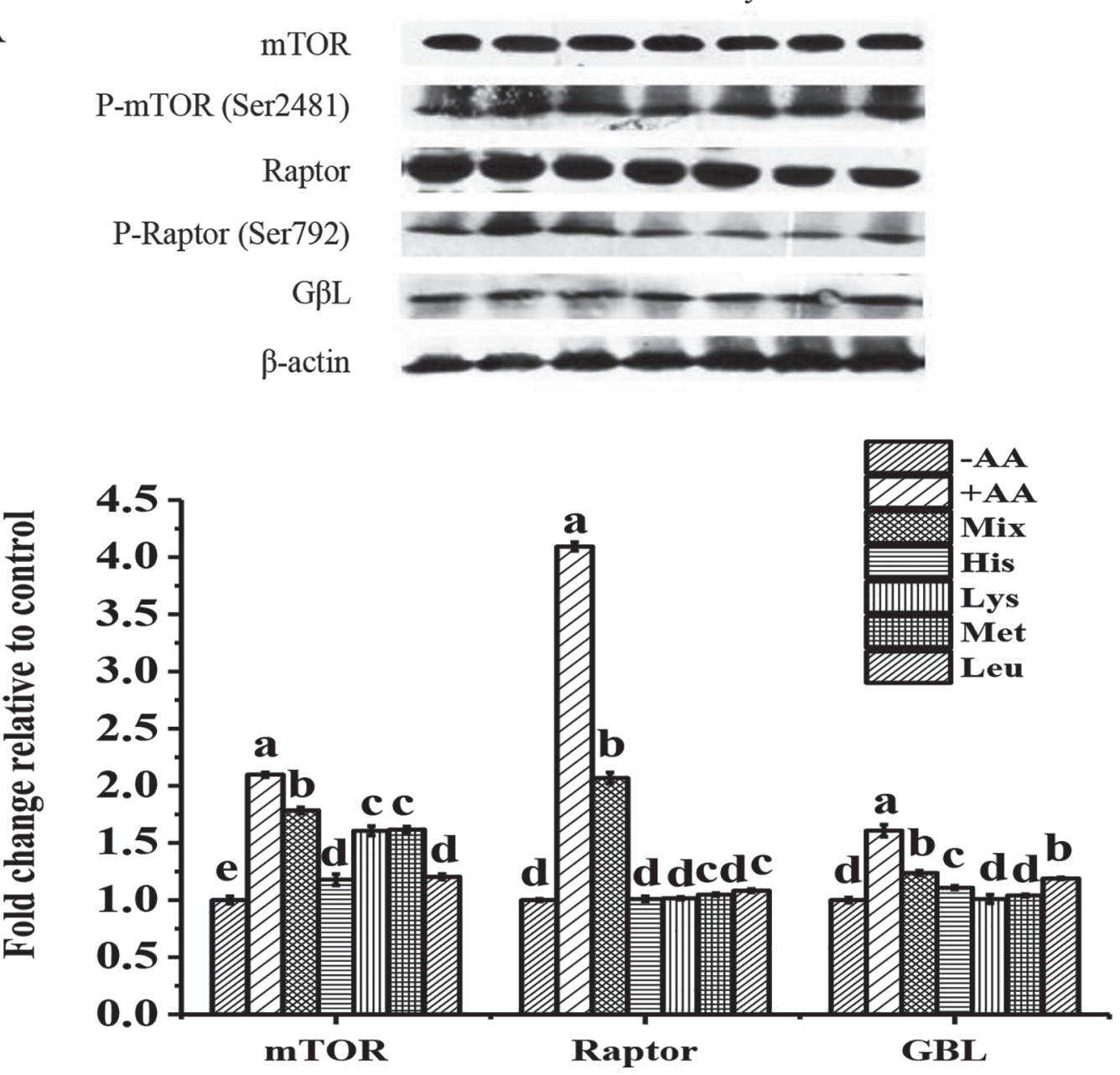

Figure 5. Experiment 4: effects of His, Lys, Met, and Leu added in combination or alone on mechanistic target of rapamycin complex 1 (mTORC1) phosphorylation in the immortalized bovine mammary epithelial cell line (CMEC-H). The mTORC1 levels were determined by immunoblot analysis after incubation for $6 \mathrm{~h}$ at the indicated concentrations (His $=0.15 \mathrm{~m} M$, Lys $=0.5 \mathrm{~m} M$, Met $=0.12 \mathrm{~m} M$, and Leu $=0.45 \mathrm{~m} M$ or their combination). $\beta$-Actin was assessed as a loading control. (A) A representative blot of mTORC1 is shown. The labels above the lanes refer to the EAA treatment. (B) Comparison of mTORC1 levels as a result of the various EAA treatments. Data represent the means \pm SEM $(\mathrm{n}=3$ per group). Means marked with different letters are significantly different $(P<0.05)$ using Tukey's multiple comparison procedure. $+\mathrm{AA}=$ in the medium with all AA. $-\mathrm{AA}=$ in the medium without AA was used as the negative control. Mix $=$ these 4 EAA as an optimal mix. mTOR $=$ mechanistic target of rapamycin. Raptor $=$ regulatory associated protein of TOR. G $\beta \mathrm{L}=\mathrm{G}$ protein $\beta$ subunit-like protein. $\mathrm{P}=$ phosphorylation. 


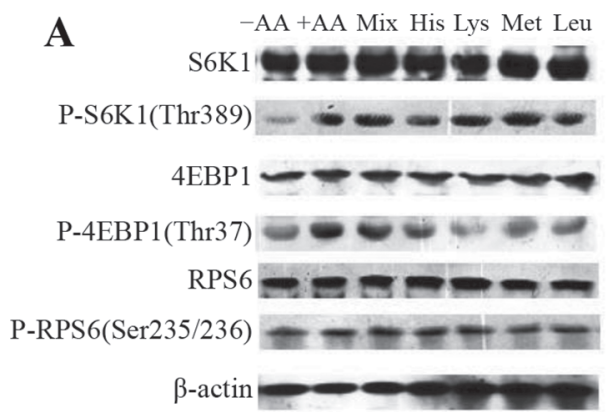

B

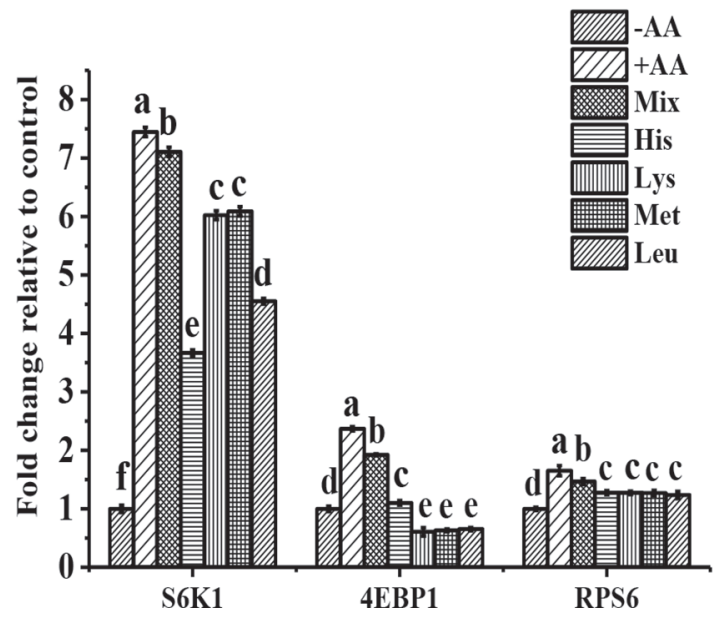

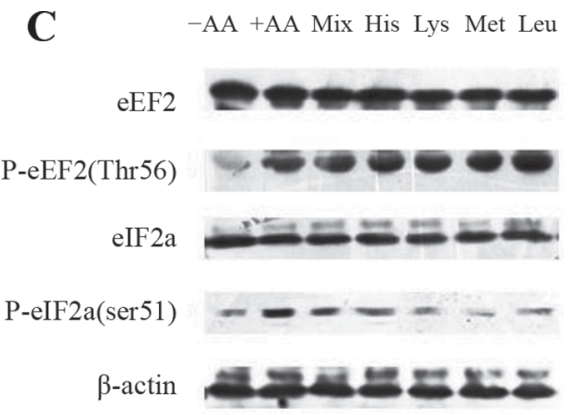

D

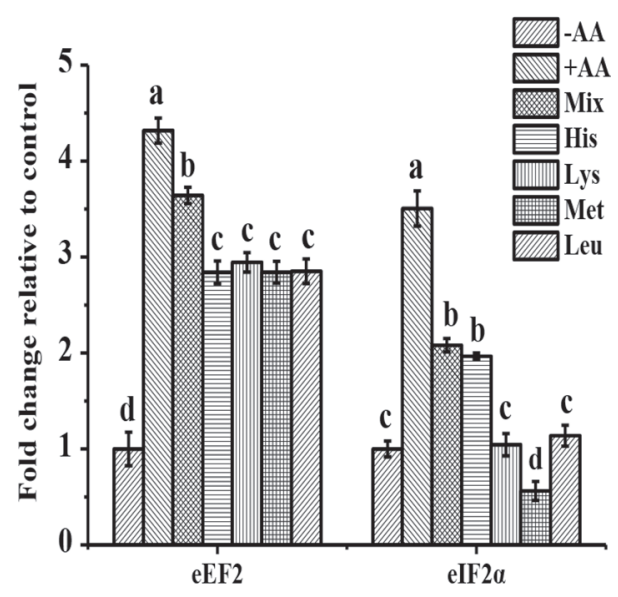

Figure 6. Experiment 4: effects of His, Lys, Met, and Leu added in combination or alone on mechanistic target of rapamycin (mTOR) downstream signaling protein phosphorylation in the immortalized bovine mammary epithelial cell (CMEC-H). These protein levels were determined by immunoblot analysis after incubation for $6 \mathrm{~h}$ at the indicated concentrations (His $=0.15 \mathrm{~m} M$, Lys $=0.5 \mathrm{~m} M$, Met $=0.12 \mathrm{~m} M$, and Leu $=$ $0.45 \mathrm{~m} M$ or their combination). $\beta$-Actin was assessed as a loading control. (A, C) Representative blots of mTOR downstream signaling proteins are shown. The labels above the lanes refer to the EAA treatment. (B, D) Comparison of mTOR downstream signaling protein levels as a result of the various EAA treatments. Data represent the means \pm SEM ( $\mathrm{n}=3$ per group). Means marked with different letters are significantly different $(P<0.05) .+\mathrm{AA}=$ in the medium with all AA. $-\mathrm{AA}=$ in the medium without AA was used as the negative control. Mix $=$ these 4 EAA as an optimal mix. S6K1 = the ribosomal protein S6 kinase 1. 4EBP1 = eukaryotic initiation factor 4E binding protein 1 . RPS6 = ribosomal protein S6. eEF2 = eukaryotic elongation factor 2 . eIF $2 \alpha=$ eukaryotic initiation factor $2 \alpha . \mathrm{P}=$ phosphorylation.

that with addition of a combination of $3 \mathrm{EAA}$ (Lys, His, and Thr), the $\beta-\mathrm{CN}$ expression value was at a maximum, but the concentration of Lys, His, and Thr in the mix was not the highest. This is similar to the findings in the present study where we found that an optimal mixture of 4 EAA (His, Lys, Met, and Leu) promoted the expression of $\beta-\mathrm{CN}$ as high as the positive control and the levels of EAA when combined were lower than the level of each EAA considered individually in their effect on cell proliferation.

The optimum EAA conditions for $\beta$-CN expression was found to be $5.47 \mathrm{~m} M$ of His, $7.48 \mathrm{~m} M$ of Lys, 1.17 $\mathrm{m} M$ of Met, and $8.21 \mathrm{~m} M$ of Leu (His:Lys:Met:Leu $=$ $5: 6: 1: 7)$ from the RSM model. Based on the multiple regression model analysis, it appears that Leu is the most effective EAA promoting the expression of $\beta-\mathrm{CN}$, and in addition Leu seems to interact negatively with Met, such that their combination is important to the produc- tion of $\beta-\mathrm{CN}$. This negative interaction may be related to the facts that both Met and Leu are neutral AA and may share the same AA transporter system in those ranges (Moshel et al., 2006). The presence of negative interaction among branched-chain AA has been known for many years. Some studies have shown that high Leu is known to negative interaction transport of Ile and Val and enhance catabolism of Ile and Val. Leucine inhibits Val uptake in lactating porcine mammary tissue (Jackson et al., 2000) and in lactating dairy mammary tissue (Haque et al., 2013). Consequently, duodenal infusions of $40 \mathrm{~g}$ of Leu/d to corn-based diets improved both milk protein content and yield on diets limiting in Lys or Met (Rulquin and Pisulewski, 2006). Our study demonstrated that the use of the optimal concentration ratio of the $4 \mathrm{EAA}$ or the optimal concentration of single EAA substantially increased $\beta$-CN expression. The order of effectiveness of the various treatments in 
promoting $\beta$-CN expression was as follows: with all AA $(+\mathrm{AA})>$ with His, Lys, Met, and Leu in the optimal ratio $(\operatorname{mix})>$ with individual AA (Leu $>$ Lys $>$ His $>$ Met) $>$ without all AA $(-\mathrm{AA})$. With previous research (Prizant and Barash, 2008; Arriola Apelo et al., 2014b; Nan et al., 2014), which is consistent with the cell proliferation responses, these observations demonstrated that $\beta-\mathrm{CN}$ expression was more sensitive toward EAA as a mix than individual EAA, and the ratio of EAA for $\beta$-CN expression was very important. The additive effects of those EAA are biologically relevant, and given the additive effects, performing animal level research assessing such additive effects appears worthwhile to improve future AA nutrition models that assist in ration formulation. It is possible to achieving high milk protein yields for low-protein diets balanced optimally for individual EAA. This way nitrogen utilization efficiency of dairy cows could be increased with less $\mathrm{N}$ excreted into the environment.

Some previous reports demonstrated that His, Lys, Met, and Leu could be via mTORC1, and its downstream effectors 4EBP1 and S6K1 regulate the translation of milk protein (Prizant and Barash, 2008; Toerien et al., 2010; Appuhamy et al., 2011). Prizant and Barash (2008) showed that P-mTOR in $\operatorname{Ser}^{2448}$ was completely inhibited by His, Lys, and Thr supplementation, but P-S6K1 at Thr $^{389}$ and P-4EBP1 at Thr ${ }^{37}$ could still be detected. Not only P-mTOR at $\operatorname{Ser}^{2448}$ (a site phosphorylated by S6K1 via a feedback loop) was an indicator of mTOR pathway activity in CMEC (Appuhamy et al., 2011, 2012), but also the P-mTOR at $\operatorname{Ser}^{2481}$ (a site of autophosphorylation; Peterson et al., 2000; Gerasimovskaya et al., 2005; Acosta-Jaquez et al., 2009; Gao et al., 2015). It has been confirmed that P-Raptor at Ser $^{792}$ is modulated by AA and associated with mTOR activation, which regulated the mTOR kinase activity (Kim et al., 2002; Hara et al., 2002). The current results indicate that compared with negative control, the expression of P-mTOR (Ser $\left.{ }^{2481}\right)$, P-Raptor $\left(\mathrm{Ser}^{792}\right)$, and G $\beta L$ were increased with the addition of His, Lys, Met, and Leu either individually or as an optimal mix. Even the phosphorylation of mTOR, Raptor, and expression of G $\beta \mathrm{L}$ all reached a peak with the mix of the 4 EAA in an optimal ratio. Raptor is a scaffold protein that recruits substrates to mTOR and any knock-down of Raptor abolishes physiological activity of mTOR. The phosphorylation trends of mTOR and Raptor should be consistent, which was evident in our study (Hara et al., 2002; Kim et al., 2002). The GßL protein binds to the mTOR kinase domain and stabilizes the interaction between Raptor and mTOR (Kim et al., 2003). In line with the enhanced mTOR activity, the optimal EAA mix enhanced G $\beta \mathrm{L}$ expression.
The S6K1 is a major downstream target of mTOR. The results from our study showed that the expression levels of P-S6K1 increased along with supplementation of His, Lys, Met, and Leu as a mix or alone. In contrast to our data, Prizant and Barash (2008) observed that His had a negative effects on P-S6K1 $\left(\mathrm{Thr}^{389}\right)$ in CMEC. Our results suggest that His may activate an additional kinase via an S6K1-independent pathway. Whether the 4 EAA are given as an optimal mix or separately, they all enhance P-RPS6 (Ser ${ }^{235 / 236}$ ) level, which is consistent with other results (Prizant and Barash, 2008). We speculate that $\beta-\mathrm{CN}$ expression is mainly regulated via phosphorylation of S6K1. In addition, 4EBP1 is another major downstream target of mTOR ( $\mathrm{Li}$ et al., 2005). Our results indicated that the addition of His, Lys, or Met to a medium without AA, individually, inhibited P-4EBP1 $\left(\mathrm{Thr}^{37}\right)$ in CMEC-H, whereas the optimized mixture of His, Lys, Met, and Leu, or His alone increases P-4EBP1 (Thr37). This discrepancy may be related to the different phosphorylation site.

Translation of mRNA is dynamic and is a primary means for controlling protein abundance in mammalian cells (Schwanhäusser et al., 2011). The eIF2 $\alpha$ mediates the initial step of mRNA translation (Li et al., 2005). Some research showed that in mammalian cells, phosphorylation of eIF $2 \alpha$ leads to preferential translation of a distinct transcription factor, activation transcription factor (ATF4), with the consequent induction of genes for AA expression, biosynthesis, and transport (Harding et al., 2000; Proud, 2005; Ameri and Harris, 2008; Yan and Lamb, 2012). Our study demonstrated that the optimum combination of 4 EAA increased P-eIF $2 \alpha$ (Figure 6D), and with the addition of Met alone, P-eIF2 $\alpha\left(\mathrm{Ser}^{51}\right)$ level was reduced. It was found that eIF $2 \alpha$ is phosphorylated on Ser $^{51}$ and may lead to preferential translation of a distinct transcription factor, with the consequent promotion of $\beta-\mathrm{CN}$ expression. The eEF2 mediated the elongation step of mRNA translation (Christophersen et al., 2002; Li et al., 2005). The phosphorylation of eEF2 is catalyzed by a highly specific protein kinase, eEF2 kinase (Wang and Proud, 2006). The stimulatory effect of supplementation with the optimized mixture of the 4 EAA or the addition of a single EAA increased the P-eEF2 in CMEC-H. It was possible that eEF2 enhances elongation when phosphorylated or dephosphorylated and in which of the 2 directions AA treatments affected eEF2.

\section{CONCLUSIONS}

The results of the current study indicate that these 4 EAA (His, Lys, Met, and Leu) may directly accelerate CMEC-H proliferation. The optimum concentrations of 
these 4 EAA: $5.47 \mathrm{mM}$ of His, $7.48 \mathrm{mM}$ of Lys, 1.17 $\mathrm{m} M$ of Met, and $8.21 \mathrm{~m} M$ of Leu (His:Lys:Met:Leu $=5: 6: 1: 7)$ efficiently promoted $\beta-\mathrm{CN}$ expression $(P$ $<0.01, \mathrm{R}^{2}=0.71$ ), which appeared to be mediated through activation of the mTORC1 signaling pathway. We found a significant interaction of Met and Leu $(P$ $<0.05$ ), where a higher response in $\beta$-CN was identified with higher levels of Leu and lower levels of Met. This suggests that an optimum combination of these 2 AA may lie outside the range of levels explored in this experiment. These findings will help to improve the optimal ratio of EAA models that aim of regulate $\beta-\mathrm{CN}$ translation in the mammary glands. However, more research is required to translate these findings to an in vivo long-term model.

\section{ACKNOWLEDGMENTS}

The authors gratefully acknowledge Gary Crow from University of Manitoba, Canada, who helped analyze the data and revise the manuscript. This work was partially funded by the Modern Agro-Industry Technology Research System of the P. R. China (nycytx-04-01; Beijing, China), the Agricultural Science and Technology Innovation Program (ASTIP-IAS12; Beijing, China), and National Key Basic Research Program of China (2011CB100805; Beijing, China). All authors read and approved the final manuscript.

\section{REFERENCES}

Acosta-Jaquez, H. A., J. A. Keller, K. G. Foster, B. Ekim, G. A. Soliman, E. P. Feener, and D. C. Fingar. 2009. Site-specific mTOR phosphorylation promotes mTORC1-mediated signaling and cell growth. Mol. Cell. Biol. 29:4308-4324.

Ameri, K., and A. L. Harris. 2008. Activating transcription factor 4. Int. J. Biochem. Cell Biol. 40:14-21.

Anthony, J. C., F. Yoshizawa, T. G. Anthony, T. C. Vary, L. S. Jefferson, and S. R. Kimball. 2000. Leucine stimulates translation initiation in skeletal muscle of postabsorptive rats via a rapamycinsensitive pathway. J. Nutr. 130:2413-2419.

Appuhamy, J. A. D. R. N., A. L. Bell, W. A. D. Nayananjalie, J. Escobar, and M. D. Hanigan. 2011. Essential amino acids regulate both initiation and elongation of mRNA translation independent of insulin in MAC-T cells and bovine mammary tissue slices. J. Nutr. 141:1209-1215.

Appuhamy, J. A. D. R. N., N. A. Knoebel, W. A. D. Nayananjalie, J. Escobar, and M. D. Hanigan. 2012. Isoleucine and leucine independently regulate mTOR signaling and protein synthesis in MAC-T cells and bovine mammary tissue slices. J. Nutr. 142:484-491.

Arriola Apelo, S. I., J. R. Knapp, and M. D. Hanigan. 2014a. Invited review: Current representation and future trends of predicting amino acid utilization in the lactating dairy cow. J. Dairy Sci. 97:4000-4017.

Arriola Apelo, S. I., L. M. Singer, X. Y. Lin, M. L. McGilliard, N. R. St-Pierre, and M. D. Hanigan. 2014b. Isoleucine, leucine, methionine, and threonine effects on mammalian target of rapamycin signaling in mammary tissue. J. Dairy Sci. 97:1047-1056.

Bionaz, M., W. Hurley, and J. Loor. 2012. Milk protein synthesis in the lactating mammary gland: Insights from transcriptomics analyses. InTech. http://cdn.intechopen.com/pdfs/38826/intechmilk_protein_synthesis_in_the_lactating_mammary_gland_ insights_from_transcriptomics_analyses.pdf.

Calvert, T., K. Aidoo, A. Candlish, and A. M. Fuat. 2005. Comparison of in vitro cytotoxicity of Fusarium mycotoxins, deoxynivalenol, T-2 toxin and zearalenone on selected human epithelial cell lines. Mycopathologia 159:413-419.

Christophersen, C. T., J. Karlsen, M. O. Nielsen, and B. Riis. 2002. Eukaryotic elongation factor-2 (eEF-2) activity in bovine mammary Tissue. J. Dairy Res. 69:205-212.

Davies, D. T., and A. J. R. Law. 1983. Variation in the protein composition of bovine casein micelles and serum casein in relation to micellar size and milk temperature. J. Dairy Res. 50:67-75.

Draper, N. R., and H. Smith. 1998. Applied Regression Analysis. 3rd ed. John Wiley and Sons, Inc., New York, NY.

Fox, P., and P. M. Sweeney. 2003. Advanced Dairy Chemistry. Vol. 1, Proteins. P. A. Kluwer Academic/Plenum, Dordrecht, the Netherlands.

Gao, H. N., H. Hu, N. Zheng, and J. Q. Wang. 2015. Leucine and histidine independently regulate milk protein synthesis in bovine mammary epithelial cells via mTOR signaling pathway. J. Zhejiang Univ. Sci. B 16:560-572.

Gerasimovskaya, E. V., D. A. Tucker, and K. R. Stenmark. 2005. Activation of phosphatidylinositol 3-kinase, Akt, and mammalian target of rapamycin is necessary for hypoxia-induced pulmonary artery adventitial fibroblast proliferation. J. Appl. Physiol. $98: 722-731$

Hanigan, M. D., L. A. Crompton, B. J. Bequette, J. A. N. Mills, and J. France. 2002. Modelling mammary metabolism in the dairy cow to predict milk constituent yield, with emphasis on amino acid metabolism and milk protein production: Model evaluation. J. Theor. Biol. 217:311-330.

Haque, M. N., H. Rulquin, A. Andrade, P. Faverdin, J. Peyraud, and S. Lemosquet. 2012. Milk protein synthesis in response to the provision of an "ideal" amino acid profile at 2 levels of metabolizable protein supply in dairy cows. J. Dairy Sci. 95:5876-5887.

Haque, M. N., H. Rulquin, and S. Lemosquet. 2013. Milk protein responses in dairy cows to changes in postruminal supplies of arginine, isoleucine, and valine. J. Dairy Sci. 96:420-430.

Hara, K., Y. Maruki, X. Long, K. I. Yoshino, N. Oshiro, S. Hidayat, and K. Yonezawa. 2002. Raptor, a binding partner of target of rapamycin (TOR), mediates TOR action. Cell 110:177-189.

Harding, H. P., I. Novoa, Y. Zhang, H. Q. Zeng, R. Wek, M. Schapira, and D. Ron. 2000. Regulated translation initiation controls stressinduced gene expression in mammalian cells. Mol. Cell 6:10991108

Hristov, A. N., W. J. Price, and B. Shafii. 2004. A meta-analysis examining the relationship among dietary factors, dry matter intake, and milk and milk protein yield in dairy cows. J. Dairy Sci. $87: 2184-2196$.

Hu, H., N. Zheng, H. N. Gao, W. T. Dai, Y. D. Zhang, S. L. Li, and J. Q. Wang. 2016. Immortalized bovine mammary epithelial cells express stem cell markers and differentiate in vitro. Cell Biol. Int.40:861-872.

Jackson, S. C., J. M. Bryson, H. Wang, and W. L. Hurley. 2000. Cellular uptake of valine by lactating porcine mammary tissue. J. Anim. Sci. 78:2927-2932.

Kim, C. H., J. J. Choung, and D. G. Chamberlain. 1999. Determination of the first-limiting amino acid for milk production in dairy cows consuming a diet of grass silage and a cereal-based supplement containing feather meal. J. Sci. Food Agric. 79:1703-1708.

Kim, C. H., J. J. Choung, and D. G. Chamberlain. 2000. Variability in the ranking of the three most-limiting amino acids for milk protein production in dairy cows consuming grass silage and a cereal-based supplement containing feather meal. J. Sci. Food Agric. 80:1386-1392.

Kim, C. H., J. J. Choung, and D. G. Chamberlain. 2001. Estimates of the efficiency of transfer of L-histidine from blood to milk when it is the first-limiting amino acid for secretion of milk protein in the dairy cow. J. Sci. Food Agric. 81:1150-1155. 
Kim, D. H., D. D. Sarbassov, and S. M. Ali. 2002. mTOR interacts with Raptor to form a nutrient-sensitive complet that signals to the cell growth machinery. Cell 110:163-175.

Kim, D. H., D. D. Sarbassov, S. M. Ali, R. R. Latek, K. V. Guntur, H. Erdjument-Bromage, and D. M. Sabatini. 2003. GßL, a positive regulator of the rapamycin-sensitive pathway required for the nutrient-sensitive interaction between raptor and mTOR. Mol. Cell 11:895-904.

Kim, E. 2009. Mechanisms of amino acid sensing in mTOR signaling pathway. Nutr. Res. Pract. 3:64-71.

Korhonen, M., A. Vanhatalo, and P. Huhtanen. 2002. Evaluation of isoleucine, leucine, and valine as a second-limiting amino acid for milk production in dairy cows fed grass silage diet. J. Dairy Sci. $85: 1533-1545$.

Lapierre, H., D. R. Ouellet, L. Doepel, G. Holtrop, and G. E. Lobley. 2008. Histidine, lysine and methionine: From metabolism to balanced dairy rations. Pages 19-36 in Proc. 44th Eastern Nutrition Conference of the Animal Nutrition Association of Canada (ANAC), University of Guelph, Guelph, ON, Canada. University of Guelph, Guelph, ON, Canada.

Li, X., I. Alafuzoff, H. Soininen, B. Winblad, and J. J. Pei. 2005. Levels of mTOR and its downstream targets 4E-BP1, eEF2, and eEF2 kinase in relationships with tau in Alzheimer's disease brain. FEBS J. 272:4211-4220.

McLean, D. M., E. R. B. Graham, R. W. Ponzoni, and H. A. McKenzie.1984. Effects of milk protein genetic variants on milk yield and composition. J. Dairy Res. 51:531-546.

Mercier, J. C., and J. L. Vilotte. 1993. Structure and function of milk protein genes. J. Dairy Sci. 76:3079-3098.

Moshel, Y., R. E. Rhoads, and I. Barash. 2006. Role of amino acids in translational mechanisms governing milk protein synthesis in murine and ruminant mammary epithelial cells. J. Cell. Biochem. 98:685-700.

Myers, R. H., and D. C. Montgomery. 2002. Response Surface Methodology. John Wiley and Sons, Hoboken, NJ.

Nan, X. M., D. P. Bu, X. Y. Li, J. Q. Wang, H. Y. Wei, H. Hu, L. Y. Zhou, and J. J. Loor. 2014. Ratio of lysine to methionine alters expression of genes involved in milk protein transcription and translation and mTOR phosphorylation in bovine mammary cells. Physiol. Genomics 46:268-275.

Park, C. S., P. T. Chandler, and R. M. Clark. 1976. Optimum amino acid complement for protein synthesis by rat mammary cells in tissue culture. J. Dairy Sci. 59:1758-1763.

Patton, S. 1969. Milk. Sci. Am. 221:58-68.

Peterson, R. T., P. A. Beal, and M. J. Comb. 2000. FKBP12-rapamycin associated protein (FRAP) autophosphorylates at serine
2481 under translationally repressive conditions. J. Biol. Chem. 275:7416-7423.

Prizant, R. L., and I. Barash. 2008. Negative effects of the amino acids Lys, His, and Thr on S6K1 phosphorylation in mammary epithelial cells. J. Cell. Biochem. 105:1038-1047.

Proud, C. G. 2005. eIF2 and the control of cell physiology. Semin. Cell Dev. Biol. 16:3-12.

Rulquin, H., and P. M. Pisulewski. 2006. Effects of graded levels of duodenal infusions of leucine on mammary uptake and output in lactating dairy cows. J. Dairy Res. 73:328.

Schwanhäusser, B., D. Busse, N. Li, G. Dittmar, J. Schuchhardt, J. Wolf, W. Chen, and M. Selbach. 2011. Global quantification of mammalian gene expression control. Nature 473:337-342.

Sestili, P., O. Cantoni, F. Cattabeni, and D. Murray. 1995. Evidence for separate mechanisms of cytotoxicity in mammalian cells treated with hydrogen peroxide in the absence or presence of L-histidine. Biochim. Biophys. Acta 1268:130-136.

Toerien, C. A., D. R. Trout, and J. P. Cant. 2010. Nutritional stimulation of milk protein yield of cows is associated with changes in phosphorylation of mammary eukaryotic initiation factor 2 and ribosomal s6 kinase 1. J. Nutr. 140:285-292.

Wang, H., Y. Ji, G. Y. Wu, K. J. Sun, Y. L. Sun, W. Li, B. Wang, B. B. He, Q. Zhang, and Z. L. Wu. 2015. L-Tryptophan activates mammalian target of rapamycin and enhances expression of tight junction proteins in intestinal porcine epithelial cells. J. Nutr. 145:1156-1162.

Wang, L., Y. Lin, Y. J. Bian, L. L. Liu, L. Shao, L. Lin, B. Qu, F. Zhao, X. J. Gao, and Q. Z. Li. 2014. Leucyl-tRNA synthetase regulates lactation and cell proliferation via mTOR signaling in dairy cow mammary epithelial cells. Int. J. Mol. Sci. 15:5952-5969.

Wang, X., and C. G. Proud. 2006. The mTOR pathway in the control of protein synthesis. Physiology (Bethesda) 21:362-369.

Wang, X., S. Qiao, Y. Yin, L. Yue, Z. Wang, and G. Wu. 2007. A deficiency or excess of dietary threonine reduces protein synthesis in jejunum and skeletal muscle of young pigs. J. Nutr. 137:1442-1446.

Weekes, T. L., P. H. Luimes, and J. P. Cant. 2006. Responses to amino acid imbalances and deficiencies in lactating dairy cows. J. Dairy Sci. 89:2177-2187.

Yan, L., and R. F. Lamb. 2012. Amino acid sensing and regulation of mTORC1. Semin. Cell Dev. Biol. 23:621-625.

Zhou, G., F. Lei, and X. Li. 2015. Optimisation of ultrasound-assisted extraction conditions for maximal recovery of active monacolins and removal of toxic citrinin from red yeast rice by a full factorial design coupled with response surface methodology. Food Chem. 170:186-192. 